\title{
Elderly Mistreatment from Family Caregivers: The hidden Factor of Elderly abuse
}

\author{
Magda Aly Mohamed ${ }^{1}$, Omaima Mohamed Elalem ${ }^{2}$, Reda Ibrahim Elmowafy ${ }^{3}$ \& Nadia Mohammed Wahba ${ }^{4}$ \\ ${ }^{1 .}$ Assist. Prof. of Family \& Community Health Nursing Department, Faculty of Nursing, Port Said University Egypt. \\ 2. Assist. Prof. of Family \& Community Health Nursing Department, Faculty of Nursing, Port Said University Egypt. \\ 3. Assist. Prof. of Family \& Community Health Nursing Department, Faculty of Nursing, Port Said University Egypt. \\ ${ }^{4 .}$ Lecturer in Psychiatric Nursing and Mental Health Department Faculty of Nursing, Port Said University Egypt.
}

\begin{abstract}
Background: Elder mistreatment is a well-recognized public health issue with complex underlying factors. A shared living arrangement for elderly people may increase the risk for abuse, particularly physical, psychological, and financial abuse. Objective: To assess the elderly mistreatment from family caregivers and their risk factors. Design: a descriptive cross-sectional. Setting: The study was carried out in twelve primary health care centers at Port-Said Governorate, and outpatient clinics for the elderly at Port Said Psychiatric Health Hospital. Participants: Sample was composed of 912 elderly persons, who were selected by the cluster sampling technique. Methods: Three tools were utilized to collect data; firstly socio-demographic characteristics of the elderly and independence scale in daily life activities. Second tool was the Vulnerability abuse screening scale, last one was elder assessment instrument. Results: The neglect was the predominant type of elder mistreatment, followed by abandonment and exploitation, while physical abuse was the least frequent. Conclusion: The results indicated that the neglect was a highly abuse domain among elderly people. Moreover, the elderly who older, dependent, and living with a caregiver are more vulnerable to mistreatment. Recommendations: There was an urgent need for developing a psycho-educational program for caregivers of elderly people about the prevention of elderly mistreatment with qualified and trained psychiatric nurses.
\end{abstract}

\section{Keywords: Abuse, Elderly mistreatment, Family caregiver \& Vulnerability.}

\section{Introduction:}

As population ageing increases in both developed and developing countries, Egypt like many other countries is undergoing a demographic transition towards an ageing society. There were 4,400,000 persons aged 60 and over representing $6.9 \%$ of the total population in 2006, while the expected percentage of older population may reach $8.9 \%$ in 2016 and $10.9 \%$ in 2026 than $12 \%$ by 2030 (Alharahsheh, 2016 \& Egypt Demographic \& Health Survey, 2015). The prevalence of elderly abuse by family caregivers is reported to be $12 \%-15 \%$ (Von et al., 2018). Elder mistreatment is a violation of human rights. It has devastating consequences for older persons such as physical, psychological or emotional, financial, sexual and neglect, loss of property, and security. It is also associated with increased mortality and morbidity. Elder mistreatment is a problem that manifests itself in both rich and poor countries and at all levels of society (WHO, 2018).

Aging is a complex process of biological, psychosocial, cultural, and experiential changes. As people get older, they may experience a decline in different psychological and social functions that expose them to emotional and physical vulnerability (Salama \& Abou ElSoud, 2018) (Dillin et al., 2014). Elder mistreatment has been defined as either of the following, an intentional action that causes harm or creates a serious risk of harm (whether or not harm is intended) to a vulnerable elder by a caregiver or other person who stands in a trust relationship to the elder and failure by a caregiver to satisfy the elder's basic needs or to protect the elder from harm (American College of Emergency Physicians, 2016) (Bagshaw et al., 2017).

Elder mistreatment includes intentional or neglectful acts by family caregivers that harm a vulnerable elderly person which can occur in a variety of settings. One out of 10 elderly experience some form of abuse or neglect by family caregivers each year, and the incidence is expected to increase (WHO, 2015).

It is estimated that $4-10 \%$ of elderlies (65 years or older) were abused by relatives, caregivers, or others. The prevalence of elderly abuse by family caregivers is reported to be $12 \%-15 \%$ (Von et al., 2018).

Several risk factors for elder mistreatment includes increased physical dependency of weak elders on caregivers, fewer family members 
Living in the same geographic region or caregivers being elderly or impaired themselves, cognitive impairment among caregivers or the mistreated as well as poverty, age, race, functional disability, frailty, loneliness and low education (Lynch, et al., 2018). Thus, elder mistreatment is not only harmful to individuals but is also detrimental to social, legal, and health systems (Blair \& Perry, 2017).

Family caregivers have a duty to help and support the elderly to enjoy their daily activities. The elderly caregivers in the family therefore play an important role in the good quality of life. (Family Caregiver Alliance, 2018). While, family caregivers have an important role, usually unpaid, in caring for elderly people. Elder abuse and neglect took place at home. About $95 \%$ of older people live on their own or with their spouses, children, siblings, or other relatives-not in institutional settings. When elder abuse happens, family, other household members, or paid caregivers are usually the abusers (Formosa, 2018).

Community and psychiatric health nurses are involved in primary, secondary, and tertiary prevention efforts for elders and family caregivers. Four major areas in which community and psychiatric health nurses play an important role in addressing elder mistreatment are the identification of suspected cases, reduction of risk and maintenance of independence, oversight, supervision, and encouragement of family caregivers, and development of support group (Nursing Home Abuse Center, 2016) (Orfila et al., 2018).

\section{Significance of the study:}

As population ageing increases in both developed \& developing countries, Egypt like many other countries is undergoing a demographic transition towards an ageing society. There were 4,400,000 persons aged 60 and over representing $6.9 \%$ of the total population in 2006, while the expected percentage of older population may reach $8.9 \%$ in 2016 and $10.9 \%$ in 2026 than $12 \%$ by 2030 (Alharahsheh, 2016 \& Egypt Demographic \& Health Survey, 2015). The prevalence of elderly abuse by family caregivers is reported to be $12 \%-15 \%$ (Von, et al., 2018). Elder mistreatment is a violation of human rights. It has devastating consequences for older persons such as physical, psychological or emotional, financial, sexual and neglect, loss of property, and security. It is also associated with increased mortality and morbidity. Elder mistreatment is a problem that manifests itself in both rich and poor countries and at all levels of society (WHO, 2018). Because of differing definitions, poor detection, and under-reporting, the extent of elder mistreatment is unknown and first gained attention as medical and social problems about years ago. In this regard, noninstitutionalized elderly who are frail and dependent are vulnerable to be abused by overwhelmed caregivers especially psychologically abusive behavior.

Aim of the study

This study aimed to assess elderly mistreatment from family caregivers and its risk factors through:

1. Determining forms of elderly mistreatment from family caregivers including physical abuse, neglect, exploitation, \& abandonment.

2. Assessing the risk factors that contribute to elderly mistreatment.

The research questions for this study were:

1. What are the most prevalent types of elderly mistreatment from family caregivers?

2. What are the factors contributing to elderly mistreatment from family caregivers?

\section{Subjects and Method \\ Study Design}

A descriptive cross-sectional research design, the study conducted from January 2019 to January 2020

Setting:

The present study was carried out in twelve primary health care centers and outpatient clinics for the elderly at Port Said Psychiatric Health Hospital. Primary health care centers affiliated to Ministry of Health, which were randomly chosen representing the six districts of Port-Said Governorate. Each of the previously mentioned centers has a chronic disease clinic that providing non-profit health care services for elderly people such as history taking, physical examination, vital signs examination, and lab investigations for blood sugar. These services are provided from 08:00 AM to 08:00 PM.

Study Subjects:

The study subjects have comprised a sample of 912 elderly persons (males and females) who attended the different outpatient clinics of the previously mentioned settings during the period of data collection. They were totally or partially dependent on the caregiver. Elderly who aged less than 60 years and those who were unable to respond properly due to any kind of difficulty as a serious illness, language barrier, unwillingness, and mentally disabled were excluded from the sample. Also, the elderly residing in long- 
term care institutions were excluded.

\section{Sampling Technique:}

A cluster sampling technique was applied to recruit the study subjects form six districts located in Port- Said Governorate, which was (ELManakh, El Dawahy, El-Zohur, El-Arab, El Gharb \& El- Ganoub) as follows: A sampling frame which includes a list of all primary health care centers of the six districts, and outpatient clinic for elderly at Port Said Psychiatric Health Hospital was developed, then two settings were selected randomly from each district.

To collect data for this study, the following tools were used:

Tool I: A Structured Interview Schedule for the elderly: This tool was comprised of two parts:

Part (I): Socio-demographic data of the elderly

This structured sheet was developed by the researcher in the Arabic language. The sheet elicits personal characteristics as gender, age, educational level, marital status, family caregiver's relationship, and pension for assessment of socioeconomic status.

Part (II): Independence Scale in Daily Life Activities:

This scale was developed by Katz, Ford, Moskowitz, Jackson \& Jaffe (2016), in the English language to evaluate the functional independence of the elderly. it is composed of 8 items. This scale was used to assess the deficits in the performance of the elderly's everyday activities in the following operating areas: bathing, dressing, toilet, transfer, salute, feeding, and living arrangement activities.

\section{Scoring System:}

A score of (27 and more) is high which means that the elderly is totally independent (full function). The score ranges between (18-26) means that the elderly is partially dependent and need assistance. While the score (less than 18) means that the elderly is totally dependent.

Tool II: Vulnerability Abuse Screening Scale (VASS):

The vulnerability abuse screening scale (VASS) was developed by Mishra and Schoffield (2003), it was a brief 12 items questionnaire designed to assess the risk of elder abuse over the past 12 months. It has 4 subscales of three questions each with yes/no response options and is supported by psychometric evaluation. These subscales were vulnerability $(1,2,3)$, dependence $(4,5,6)$, dejection $(7,8,9)$, and coercion $(10,11,12)$.
Scoring System:

The total score varies from 0 to 12 , scores more than 4 to 7 are indicative of the risk of abuse, and scores higher than 7 points interpreted as the elderly at a higher risk of being mistreated. The point score of the scale is obtained through the sum of the values assigned to each affirmative answer, except for items 4, 5, and 6, which score in the event of a negative answer. The VASS is designed for self-completion by older adults and has been validated on a large population-based sample. The scale showed satisfactory Internal consistency, with Cronbach's Alpha $\alpha=0.74$. (Ayalon, 2011).

Tool III: The Elder Assessment Instrument (EAI): The Elder Assessment Instrument (EAI) was developed by Fulmer, Guadagno, Paveza, VandeWeerd \& Baglioni et al., (2003). It included 41- items screening tool with both subjective and objective items to determine if an older person should be referred for suspected elder mistreatment. It was divided into groups of questions, each group of questions measures one type of elder mistreatment including physical, psychological, and financial. The scale has a sensitivity of $71 \%$ and specificity of $93 \%$. The scale is considered easy to administer in clinical settings. The internal consistency reliability (Cronbach's alpha) is reported at0.84 in a sample of 501 older adults who presented in an emergency department setting. The validity and reliability were done by the author.

\section{Scoring System}

There is no published scoring system so it relies on clinician judgment. A person referred to social services if the following exists: If there is any evidence of mistreatment without sufficient clinical explanation, whenever there is a subjective complaint by the elder of elder mistreatment or whenever the clinician believes there is high risk or probable abuse, neglect, exploitation, abandonment (Fulmer, Guadagno, Paveza, VandeWeerd \& Baglioni et al., 2003).

Content Validity:

It was ascertained by a jury consisting of five experts who decided that the translated tools were valid. They were selected based on their qualifications and experience in Psychiatric nursing, research, and education. They were requested to express their opinions regarding clarity, relevance, comprehensiveness, and construction of the translated tools. The required corrections and modifications were carried out accordingly. Also, the translated tools were translated by the researcher from the English 
language to Arabic and retranslated to English language, then it was presented to experts in the English language to ensure that the translation is correct and gives the same meaning.

\section{Reliability of the Tools:}

Cronbach Alpha coefficient was calculated to assess the reliability of the translated tools through their internal consistency. the tools were proved to be reliable as the Independence Scale in Daily Life Activities has demonstrated a high internal consistency (Cronbach $\alpha$ ranged from0.79 to 0.88). The reliability of the Vulnerability Abuse Screening Scale (VASS) was $\alpha=0.83$. and the Elder Assessment Instrument Scale showed a satisfactory internal consistency, with $\alpha=0.80$.

Pilot study:

The pilot study was carried out on $10 \%$ of study sample which included (91) elderly persons, who were selected randomly. It was done to ascertain the relevance, clarity, and applicability of the used tools and to estimate the time needed to fill in the data collection tools. The elderly persons who shared in the pilot study were excluded from the main study sample to assure the stability of the result. Based on the findings of the pilot study, no modifications were done to the tools. It was simple and clear. The pilot study was conducted on the first of October
2018 for two months.

\section{Ethical considerations:}

The study was approved by the Scientific Research Ethics Committee of the Faculty of Nursing, Port Said University. An informal verbal consent was obtained from elderly persons after a complete description of the purpose and nature of the study. Confidentiality was assured to each elderly person, and they were informed that the collected data will be used only for the research purpose and anonymity was guaranteed. The studied participants were informed that their participation is voluntary and they have the right to withdraw from the study at any time.

\section{Data analysis:}

Data were collected, tabulated, and statistically analyzed by an IBM compatible personal computer with SPSS statistical package version 24. Normally distributed quantitative data were analyzed by t-test (between 2 groups) and ANOVA (for more than 2 groups). Odd's Ratio (OR) was calculated for significant risk factors at CI 95\%. P-Value of $<0.05$ was considered statistically significant. Logistic regression models were used to identify factors associated with the risk of elderly mistreatment from family caregivers.

\section{Results:}

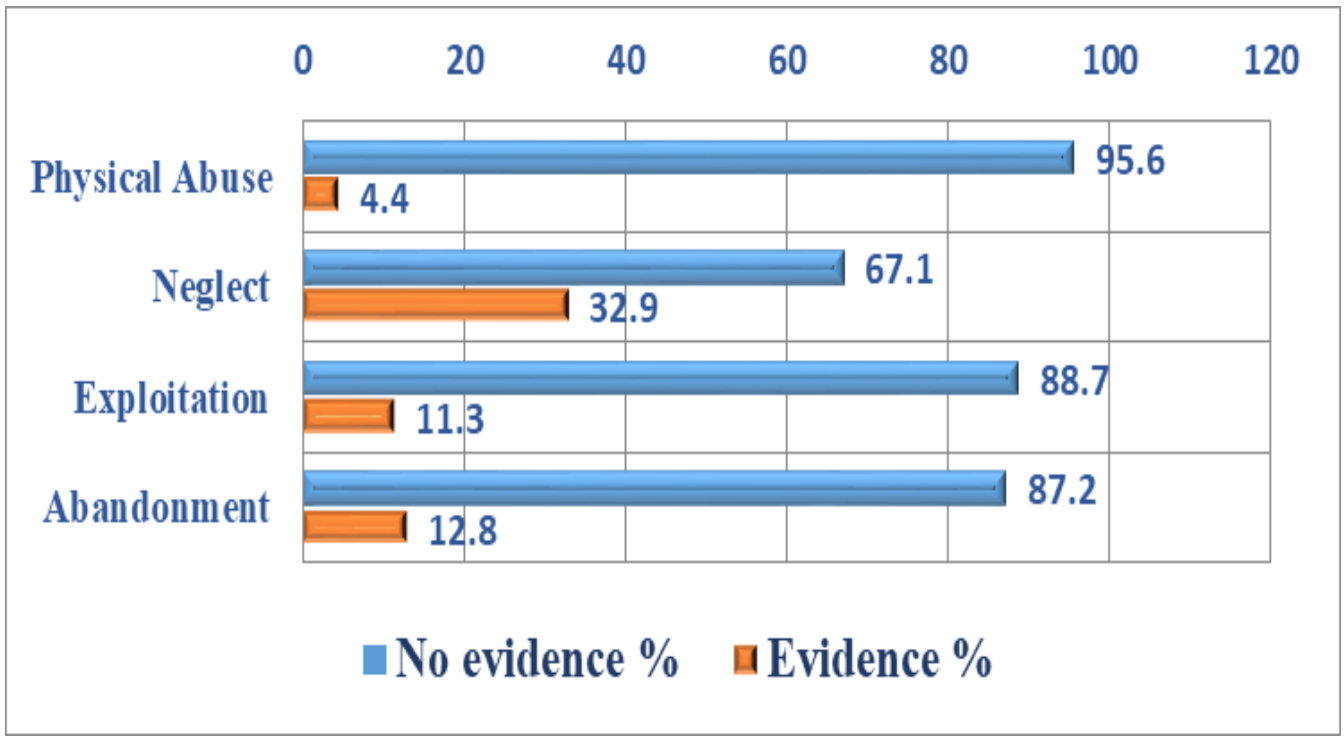

Figure (1): Types of elder mistreatment among the studied elderly people $(\mathrm{n}=912)$ 
Table (1): Distribution of the studied elderly people according to abuse vulnerability (n=912)

\begin{tabular}{|c|c|c|c|c|}
\hline \multirow{2}{*}{ Items } & \multicolumn{2}{|c|}{ Yes } & \multicolumn{2}{|c|}{ No } \\
\hline & $\mathbf{N}$ & $\%$ & $\mathbf{N}$ & $\%$ \\
\hline \multicolumn{5}{|l|}{ Vulnerability } \\
\hline Are you afraid of anyone in your family? & 28 & 4.8 & 553 & 95.2 \\
\hline Has anyone close to you tried to hurt you or harm you recently? & 24 & 4.1 & 557 & 95.9 \\
\hline $\begin{array}{l}\text { Has anyone close to you called you names or put you down or made you feel } \\
\text { bad recently }\end{array}$ & 24 & 4.1 & 557 & 95.9 \\
\hline \multicolumn{5}{|l|}{ Dependence } \\
\hline Do you have enough privacy at home? & 469 & 80.7 & 112 & 19.3 \\
\hline Do you trust most of the people in your family? & 502 & 86.4 & 79 & 13.6 \\
\hline Can you take your own medication and get around by yourself? & 485 & 83.5 & 96 & 16.5 \\
\hline \multicolumn{5}{|l|}{ Dejection } \\
\hline Are you sad or lonely often? & 135 & 23.2 & 446 & 76.8 \\
\hline Do you feel that nobody wants you around? & 51 & 8.8 & 530 & 91.2 \\
\hline Do you feel uncomfortable with anyone in your family? & 85 & 14.6 & 496 & 85.4 \\
\hline \multicolumn{5}{|l|}{ Coercion } \\
\hline Does someone in your family make you stay in bed or tell you you're sick? & 55 & 9.5 & 526 & 90.5 \\
\hline Has anyone forced you to do things you didn't want to do? & 34 & 5.9 & 547 & 94.1 \\
\hline Has anyone taken things that belong to you without your OK? & 40 & 6.9 & 541 & 93.1 \\
\hline \multicolumn{5}{|l|}{ Total } \\
\hline High risk & 838 & 91.9 & 74 & 8.1 \\
\hline Less risk & 74 & 8.1 & 838 & 91.9 \\
\hline
\end{tabular}

Table (2): Relationship between types of elder mistreatment and socio-demographic characteristics of the studied elderly people.

\begin{tabular}{|c|c|c|c|c|c|c|}
\hline \multirow{3}{*}{$\begin{array}{c}\text { Socio- } \\
\text { demographic } \\
\text { characteristics }\end{array}$} & & & \multicolumn{4}{|c|}{ Types of elder mistreatment } \\
\hline & & & \multirow{2}{*}{$\begin{array}{c}\begin{array}{c}\text { Physical } \\
\text { Abuse }\end{array} \\
\text { Mean } \pm \text { SD. } \\
\end{array}$} & \multirow{2}{*}{$\begin{array}{c}\text { Neglect } \\
\text { Mean } \pm \text { SD. }\end{array}$} & \multirow{2}{*}{$\begin{array}{c}\text { Exploitation } \\
\text { Mean } \pm \text { SD. }\end{array}$} & \multirow{2}{*}{$\begin{array}{c}\text { Abandonment } \\
\text { Mean } \pm \text { SD } \\
\end{array}$} \\
\hline & $\mathbf{N}$ & $\%$ & & & & \\
\hline \multicolumn{7}{|l|}{ Gender } \\
\hline Male & 582 & 63.8 & $10.18 \pm 3.10$ & $16.82 \pm 4.42$ & $6.35 \pm 3.60$ & $3.97 \pm 2.69$ \\
\hline Female & 330 & 36.2 & $9.87 \pm 2.53$ & $18.17 \pm 5.54$ & $5.91 \pm 2.91$ & $4.19 \pm 2.95$ \\
\hline $\mathbf{T}(\mathbf{P})$ & & & $1.611(0.108)$ & $3.778 *(<001)$ & $2.011^{*}\left(0.045^{*}\right)$ & $1.128(0.260)$ \\
\hline \multicolumn{7}{|l|}{ Age in years } \\
\hline $65-<74$ & 564 & 61.8 & $10.01 \pm 2.83$ & $16.61 \pm 4.01$ & $6.21 \pm 3.31$ & $3.78 \pm 2.42$ \\
\hline 74- 84 & 254 & 27.9 & $10.07 \pm 2.92$ & $18.29 \pm 5.85$ & $5.88 \pm 2.92$ & $4.32 \pm 3.08$ \\
\hline \multirow{2}{*}{$\begin{array}{l}>85 \\
\text { Mean } \pm \text { SD }\end{array}$} & 94 & 10.3 & \multirow{2}{*}{$10.37 \pm 3.38$} & \multirow{2}{*}{$18.88 \pm 6.03$} & \multirow{2}{*}{$6.89 \pm 4.58$} & \multirow{2}{*}{$4.88 \pm 3.65$} \\
\hline & \multicolumn{2}{|c|}{$74.03 \pm 6.92$} & & & & \\
\hline $\mathbf{F}(\mathbf{p})$ & & & $0.615(0.541)$ & $16.269^{\circ}(<0.00)$ & $3.168^{\circ}\left(0.043^{*}\right)$ & $8.157^{\circ}\left(<0.001^{*}\right)$ \\
\hline \multicolumn{7}{|l|}{ Level of Education } \\
\hline Illiterate & 351 & 38.5 & $10.07 \pm 2.88$ & $18.15 \pm 5.55$ & $6.15 \pm 3.39$ & $4.37 \pm 3.17$ \\
\hline Read and write & 135 & 14.8 & $9.64 \pm 1.92$ & $17.30 \pm 4.53$ & $5.71 \pm 2.65$ & $4.14 \pm 2.81$ \\
\hline Primary level & 189 & 20.7 & $10.31 \pm 3.13$ & $16.75 \pm 4.23$ & $5.56 \pm 1.92$ & $3.56 \pm 2.06$ \\
\hline Secondary level & 136 & 14.9 & $10.20 \pm 3.30$ & $16.96 \pm 4.72$ & $7.08 \pm 4.15$ & $3.96 \pm 2.73$ \\
\hline Graduate & 71 & 7.8 & $10.30 \pm 3.61$ & $16.35 \pm 3.41$ & $6.76 \pm 4.74$ & $3.55 \pm 2.05$ \\
\hline Post graduate & 30 & 3.3 & $9.27 \pm 1.28$ & $14.83 \pm 4.36$ & $7.33 \pm 4.20$ & $4.47 \pm 3.17$ \\
\hline $\mathbf{F}(\mathbf{p})$ & & & $1.444(0.206)$ & $4.882\left(<0.001^{\prime \prime}\right)$ & $4.9799^{*}\left(<0.001^{*}\right)$ & $2.794(0.016)$ \\
\hline \multicolumn{7}{|l|}{ Marital status } \\
\hline Single & 75 & 8.2 & $10.93 \pm 4.11$ & $17.24 \pm 5.04$ & $7.52 \pm 5.10$ & $5.17 \pm 3.82$ \\
\hline Married & 588 & 64.5 & $9.87 \pm 2.67$ & $16.49 \pm 4.11$ & $6.03 \pm 3.03$ & $3.55 \pm 2.03$ \\
\hline Widow(er) & 216 & 23.7 & $10.24 \pm 3.01$ & $18.87 \pm 5.74$ & $5.95 \pm 2.90$ & $4.72 \pm 3.42$ \\
\hline Divorce & 33 & \begin{tabular}{|l|}
3.6 \\
\end{tabular} & $10.45 \pm 2.84$ & $21.76 \pm 6.61$ & $7.67 \pm 5.57$ & $6.00 \pm 4.31$ \\
\hline$\overline{F(p)}$ & & & $3.614^{*}\left(0.013^{*}\right)$ & $23.449 "(<0.001 ")$ & $6.981^{\prime \prime}\left(<0.001^{*}\right)$ & $21.346^{\prime \prime}\left(<0.001^{*}\right)$ \\
\hline \multicolumn{7}{|l|}{ Pension } \\
\hline Sufficient & 388 & 42.5 & $10.26 \pm 2.99$ & $17.83 \pm 5.38$ & $6.39 \pm 3.67$ & $4.39 \pm 3.16$ \\
\hline Insufficient & 524 & \begin{tabular}{|l|}
57.5 \\
\end{tabular} & $9.92 \pm 2.85$ & $16.93 \pm 4.47$ & $6.04 \pm 3.12$ & $3.79 \pm 2.44$ \\
\hline $\mathbf{t}(\mathbf{p})$ & & & $1.735(0.083)$ & $2.686\left(0.007^{*}\right)$ & $1.484(0.138)$ & $3.098(0.002)$ \\
\hline
\end{tabular}




\begin{tabular}{|c|c|c|c|c|c|c|}
\hline \multirow{3}{*}{$\begin{array}{c}\text { Socio- } \\
\text { demographic } \\
\text { characteristics }\end{array}$} & & & \multicolumn{4}{|c|}{ Types of elder mistreatment } \\
\hline & & & \multirow{2}{*}{$\begin{array}{c}\begin{array}{c}\text { Physical } \\
\text { Abuse }\end{array} \\
\text { Mean } \pm \text { SD. } \\
\end{array}$} & \multirow{2}{*}{$\begin{array}{c}\text { Neglect } \\
\text { Mean } \pm \text { SD. }\end{array}$} & \multirow{2}{*}{$\begin{array}{c}\text { Exploitation } \\
\text { Mean } \pm \text { SD. } \\
\end{array}$} & \multirow{2}{*}{$\begin{array}{c}\text { Abandonment } \\
\text { Mean } \pm \text { SD } \\
\end{array}$} \\
\hline & $\mathbf{N}$ & $\%$ & & & & \\
\hline \multicolumn{7}{|c|}{ Living Arrangement } \\
\hline Lived with family & 819 & 89.8 & $9.97 \pm 2.73$ & $16.95 \pm 4.40$ & $6.11 \pm 3.20$ & $3.75 \pm 2.37$ \\
\hline $\begin{array}{l}\text { Lived with } \\
\text { relative }\end{array}$ & 43 & 4.7 & $10.47 \pm 4.02$ & $20.42 \pm 7.34$ & $6.72 \pm 4.00$ & $6.51 \pm 4.40$ \\
\hline Lived alone & 50 & 5.5 & $11.26 \pm 4.25$ & $20.48 \pm 7.41$ & $7.10 \pm 4.97$ & $6.76 \pm 4.38$ \\
\hline $\mathbf{F}(\mathbf{p})$ & & & $5.088^{*}\left(0.006^{*}\right)$ & $22.339 *(<0.001 *$ & $2.621(0.073)$ & $50.025^{*}\left(<0.001^{*}\right)$ \\
\hline \multicolumn{7}{|c|}{ Activities of daily Living } \\
\hline Independent & 648 & 71.1 & $9.91 \pm 2.77$ & $16.24 \pm 3.69$ & $5.81 \pm 2.76$ & $3.74 \pm 2.39$ \\
\hline $\begin{array}{l}\text { Partially } \\
\text { dependent }\end{array}$ & 197 & 21.6 & $10.50 \pm 3.16$ & $19.62 \pm 5.69$ & $7.14 \pm 4.56$ & $4.88 \pm 3.54$ \\
\hline \multirow{2}{*}{$\begin{array}{l}\text { Totally dependent } \\
\text { Mean SD }\end{array}$} & 67 & 7.3 & \multirow[t]{2}{*}{$10.28 \pm 3.34$} & \multirow[t]{2}{*}{$20.85 \pm 7.81$} & \multirow[t]{2}{*}{$7.10 \pm 3.93$} & \multirow[t]{2}{*}{$4.58 \pm 3.28$} \\
\hline & 24.7 & & & & & \\
\hline $\mathbf{F}(\mathbf{p})$ & & & $3.358^{*}\left(0.035^{*}\right)$ & $62.292(<0.00)$ & $15.005^{*}\left(<0.00^{*}\right)$ & $14.568^{*}\left(<0.001^{*}\right)$ \\
\hline
\end{tabular}

$t$ : Student $t$-test, $F$ : value for ANOVA test, $\quad p: p$-value for comparing between different categories,

*: Statistically significant at $p \leq 0.05$

Table (3): Correlation between types of elder mistreatment and abuse vulnerability among the studied elderly people.

\begin{tabular}{|c|c|c|c|c|c|}
\hline \multirow{2}{*}{\multicolumn{2}{|c|}{ Abuse vulnerability }} & \multicolumn{4}{|c|}{ Types of mistreatment } \\
\hline & & Abuse & Neglect & Exploitation & Abandonment \\
\hline Total Vulnerability & $\begin{array}{l}\mathbf{r} \\
\mathbf{p}\end{array}$ & $\begin{array}{l}0.121^{*} \\
<0.001^{*}\end{array}$ & $\begin{array}{l}0.271^{*} \\
<0.001^{*}\end{array}$ & $\begin{array}{l}0.289^{*} \\
<0.001^{*}\end{array}$ & $\begin{array}{l}0.348^{*} \\
<0.001^{*}\end{array}$ \\
\hline Total Dejection & $\begin{array}{l}\mathbf{r} \\
\mathbf{p}\end{array}$ & $\begin{array}{l}0.068^{*} \\
0.040^{*}\end{array}$ & $\begin{array}{l}0.301^{*} \\
<0.001^{*}\end{array}$ & $\begin{array}{l}0.153^{*} \\
<0.001^{*}\end{array}$ & $\begin{array}{l}0.333^{*} \\
<0.001^{*}\end{array}$ \\
\hline Total Coercion & $\begin{array}{l}\mathbf{r} \\
\mathbf{p}\end{array}$ & $\begin{array}{l}0.058 \\
0.078\end{array}$ & $\begin{array}{l}0.334^{*} \\
<0.001^{*}\end{array}$ & $\begin{array}{l}0.285^{*} \\
<0.001^{*}\end{array}$ & $\begin{array}{l}0.407^{*} \\
<0.001^{*}\end{array}$ \\
\hline Total Dependence & $\begin{array}{l}\mathbf{r} \\
\mathbf{p}\end{array}$ & $\begin{array}{l}0.143^{*} \\
<0.001^{*}\end{array}$ & $\begin{array}{l}0.400^{*} \\
<0.001^{*}\end{array}$ & $\begin{array}{l}0.325^{*} \\
<0.001^{*}\end{array}$ & $\begin{array}{l}0.270^{*} \\
<0.001^{*}\end{array}$ \\
\hline $\begin{array}{c}\text { Overall abuse } \\
\text { vulnerability }\end{array}$ & $\begin{array}{l}\mathbf{r} \\
\mathbf{p}\end{array}$ & $\begin{array}{l}0.128^{*} \\
<0.001\end{array}$ & $\begin{array}{l}0.461^{*} \\
<0.001^{*}\end{array}$ & $\begin{array}{l}0.360^{*} \\
<0.001^{*}\end{array}$ & $\begin{array}{l}0.486^{*} \\
<0.001^{*}\end{array}$ \\
\hline
\end{tabular}

Table (4): Univariate and multivariate logistic regression analysis of factors affecting elder mistreatment

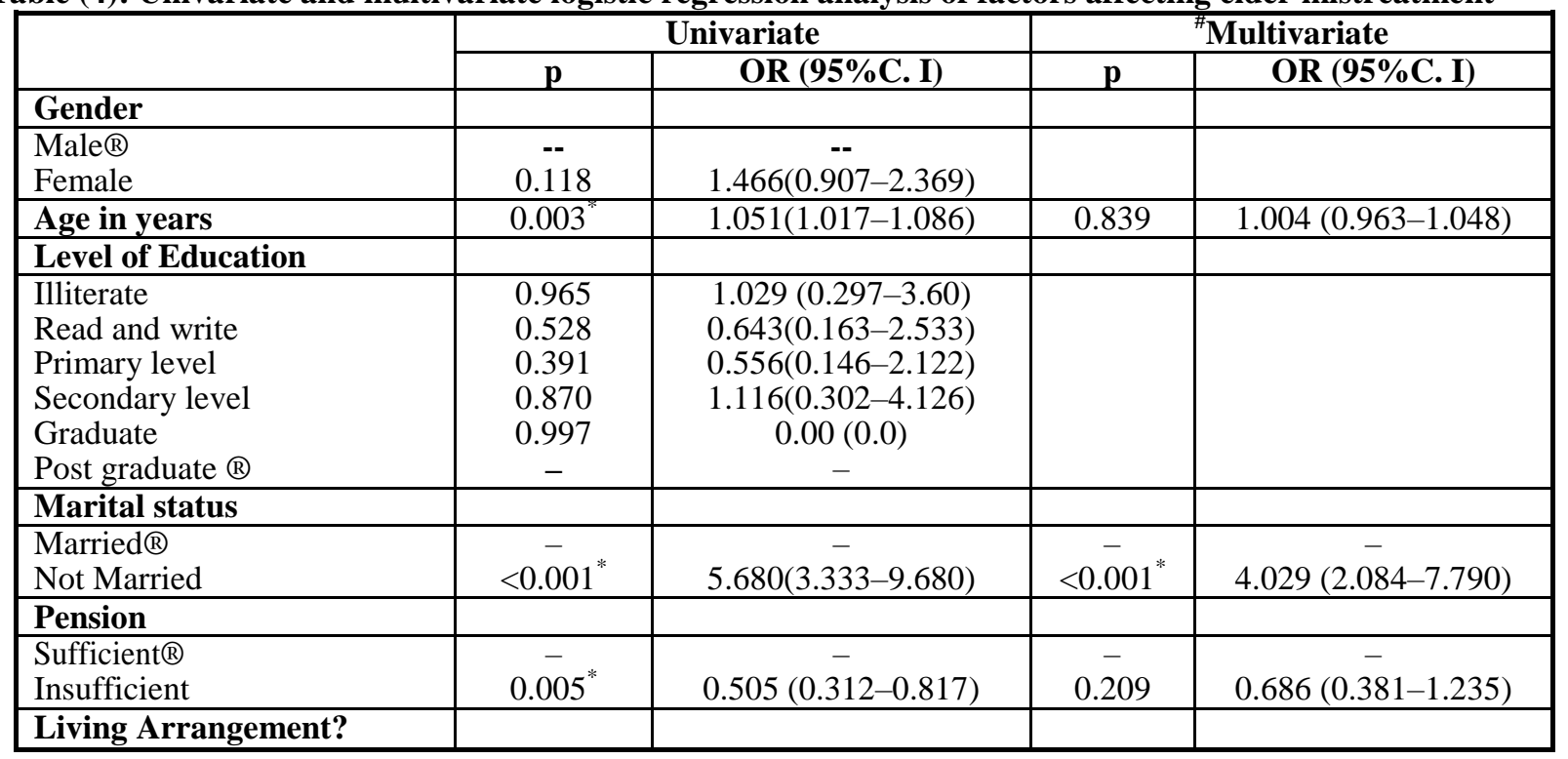




\begin{tabular}{|c|c|c|c|c|}
\hline & \multicolumn{2}{|c|}{ Univariate } & \multicolumn{2}{|c|}{${ }^{\#}$ Multivariate } \\
\hline & $\mathbf{p}$ & OR (95\% C. I) & $\mathbf{p}$ & OR (95\% C. I) \\
\hline Lived with family® & - & - & & \\
\hline Lived with relative & $<0.001^{*}$ & $5.070(2.418-10.31)$ & 0.635 & $1.270(0.474-3.404)$ \\
\hline Lived alone & $<0.001^{*}$ & $4.160(2.014-8.596)$ & 0.568 & $0.742(0.266-2.068)$ \\
\hline \multicolumn{5}{|c|}{ Activities in daily Life } \\
\hline Independent $₫$ & - & - & & \\
\hline Partially dependent & $<0.001^{*}$ & $3.614(2.518-6.054)$ & 0.261 & $1.454(0.757-2.792)$ \\
\hline Totally dependent & $<0.001^{*}$ & $2.892(1.319-6.338)$ & 0.967 & $0.978(0.342-2.797)$ \\
\hline \multicolumn{5}{|c|}{ Abuse of older persons } \\
\hline Abuse & $<0.001^{*}$ & $1.127(1.064-1.194)$ & 0.597 & $1.022(0.942-1.109)$ \\
\hline Neglect & $<0.001^{*}$ & $1.202(1.154-1.252)$ & $0.006^{*}$ & $1.084(1.024-1.148)$ \\
\hline Exploitation & $<0.001^{*}$ & $1.230(1.173-1.290)$ & $<0.001^{*}$ & $1.146(1.082-1.214)$ \\
\hline Abandonment & $<0.001^{*}$ & $1.391(1.308-1.478)$ & $<0.001^{*}$ & $1.202(1.112-1.299)$ \\
\hline
\end{tabular}

Gender $(1=$, male, $2=$ female $)$, Marital status $(1=$ not Married, $0=$ Married $)$,

Pension $=(1=$ Sufficient, $2=$ Insufficient $)$ OR: Odd's ratio

C.I: Confidence interval $\quad$ LL: Lower limit $\quad$ *: Statistically significant at $p \leq 0.05$

UL: Upper Limit \#: All variables with $p<0.05$ was included in the multivariate

Figure (1): Displays that the most type of elder mistreatment among the studied subjects was neglect (32.9\%), followed by abandonment, and exploitation which constituted $12.8 \%$ and $11.3 \%$ respectively.

Table (1): Reveals that almost one-quarter of the studied subjects $(23.2 \%)$ mentioned that they feeling sad or lonely. Concerning dependence, the majority of the studied elderly had enough privacy at home, trusted most of the people in the family, and took their own medication and got around by themselves constituting $80.7 \%, 86.4$, and $83.5 \%$ respectively. It was evidenced that, the majority of the studied elderly $(91.9 \%)$ at a lesser risk of being mistreated, while the rest of them $(8.1 \%)$ at a higher risk of being mistreated. Finally, shows that the majority of the studied subjects (91.9\%) were at higher risk of being mistreated.

Table (2): Presents that the sample included 912 elderly people, mean age was $74.03 \pm 6.92$ years; more than half of them $(61.8 \%)$ were in the age group between 65 to less than 75 years. Results revealed that less than two-thirds of them $(63.8 \%)$ were males. Related educational level, $38.5 \%$ were illiterate. Around two-thirds of the studied $(64.5 \%)$ were married. In relation to the family caregiver's relationship, it was found that almost half of the elderly's family caregivers (48.2\%) were children, and $29.8 \%$ were a spouse. Regarding pension, $57.5 \%$ of them stated that they didn't have a monthly sufficient pension. Most are better of the studied subjects $(89.8 \%)$ living with their families. As indicated, less than three-quarters $(71.1 \%)$ of the elderly were independent on their own selves and $21.6 \%$ were partially dependent. Also, there were statistically significant relations between physical abuse and marital status, living arrangement, and activities of daily living. Also, there were statistically significant relations between all socio-demographic characteristics and neglect. It was obvious that there were statistically significant relations between exploitation and all socio-demographic characteristics except pension and living arrangement. Finally, there were statistically significant relations between all socio-demographic variables except gender and age of elderly participants and abandonment at $\mathrm{p} \leq 0.05$

Table (3): Illustrates that there was a statistically significant correlation between overall abuse vulnerability and all types of elder mistreatment including physical abuse, neglect, exploitation, and abandonment $" \mathrm{r} "=0.128,0.461,0.360$, and 0.486 respectively.

Table (4): Reveals that most factor affecting elder mistreatment among elderly people was (Marital status) as unmarried are at more risk for mistreatment with were over twice as four times (OR 5.680, 95\% CI 3.333-9.680) than married. Exploitation and abandonment are more risks for mistreatment at one time (OR 1.391, 95\% CI 1.308-1.478) than nonexploitation or non- abandonment. Also, neglect is more risk for mistreatment at one time (OR 1.202, 95\% CI 1.154- 1.252) than non-neglect.

\section{Discussion:}

Elder mistreatment is being recognized increasingly as a health and psychological phenomenon. The widespread prevalence of this phenomenon among the elderly indicates the urgent need to recognize this problem and support vulnerable elderly people (American Psychological Association, 2014) (Mehra et al., 2019). This study was based on 912 elderly adults. It aimed to evaluate the magnitude of elderly mistreatment from family caregivers and its risk factors at Port Said City. This aim was significantly achieved through the present study 
findings within the frame of previously mentioned research questions.

The current study revealed that neglect was the predominant type of elder mistreatment, followed by abandonment and exploitation. On the other hand, physical abuse was the least frequent. This sequence in the types of mistreatment among the elderly may be due to shifting from family breadwinner to a person needs support, which leads to limit of independence under the pretext of affection and keenness as a part of social culture. These results were similar with the study conducted at Egypt by Abdelmoneium \& Alharahsheh, (2016), who stated that the prevailing type of mistreatment among the elderly was neglect, followed by exploitation. In addition, Solanki et al., (2015), found that the prevailing type of reported mistreatment was negligence followed by exploitation, abandonment, and physical mistreatment.

While in contrast with Ahmed et al., (2015), who studied patterns of physical, emotional, and financial of elderly mistreatment in a rural community in Egypt, and Lachera et al., (2016), who asserted that exploitation was the predominant type of older mistreatment followed by psychological and physical mistreatment. Likewise et al., (2011), stated that financial exploitation is the most common form of mistreatment of the elderly. Similarly, Yon et al., (2017), who found that exploitation was more prevalent than other types.

According to the vulnerability of the study sample to mistreatment, the findings of the present study revealed that there were statistically significant relations between physical abuse and marital status, living arrangement, and activities of daily living. Living arrangements, such as lack of privacy, have been linked to conflict within families. Although abuse can occur when the aggressor and the elderly who suffer from physical abuse live separately, the older person is more at risk when living with the caregiver. On the same line, the unmarried elderly (widowed and divorced) and who dependent on others are more vulnerable to mistreatment too.

The present study showed that neglect was associated with people over the age of 74, women, illiterate, and single (widows and divorced), who lived alone in the home and were completely dependent. This can be explained by anxious family relationships which can be exacerbated by stress and frustration when the older person becomes more dependent and cause huge burden. Naughton et al. (2012), who studied the neglect of elderly people in Ireland support these findings and reported that many risk factors were found to be associated with elderly mistreatment such as widowed, divorced, single, who suffered from physical disability and labor-intensive work, depending on insufficient income, and living alone significantly increased the risk of elderly mistreatment. In this respect, a study conducted in Egypt by Ahmed et al. (2015), illustrated that abuse of the elderly was associated with people over the age of 74, women, illiterate, unmarried, lived alone at home, and had disabilities.

As far as financial exploitation is concerned, this study depicted that being over 74 years old, male, illiterate, living alone, and relying on income constitutes a great relationship with exploitation. These results confirmed by Price et al. (2011), who claimed that exploitation was associated with a physical disability and chronic disease. These finding can be explained that physical disabilities and chronic diseases needed high budget for medication and clinical examination which caused inability to manage his/her money and lead to financial exploitation.

Regarding abandonment, the study showed that abandonment is associated with the age of 74 , illiterate, unmarried, and who lives alone at home. This result is cohort by Acierno et al. (2010), who claimed that abandonment was closely related to age, widow, divorce, individual, separation, living alone, relying solely on income alone, chronic diseases, physical disability, and depression.

The present study revealed that there was a statistically significant correlation between overall abuse vulnerability and all types of elder mistreatment. Elder mistreatment is a serious problem that needs more attention from lawmakers, public agencies, faith communities, and caregivers.

\section{Conclusion:}

Based on the findings of the present study can be concluded that elderly mistreatment is a social and psychological phenomenon. Moreover, it can take many forms including physical abuse, neglect, financial exploitation, and abandonment. Neglect was the predominant type of elder mistreatment among elderly people. The study also concluded that the neglect was a highly abuse domain among elderly people. Moreover, the elderly who older, dependent, and living with a caregiver are more vulnerable to mistreatment.

\section{Recommendations:}

Developing psycho-educational programs for caregivers of elderly people about the prevention of elderly mistreatment with qualified and trained psychiatric nurses. An approach that emphasizes empathy and empowerment of elderly people and family caregivers in health care delivery is a driving principle that has sustained an early intervention of elderly mistreatment. Family caregivers playing a 
crucial role in the treatment plans of elderly people. Therefore, it is important to assess the burden among the caregivers in order to treat them and prevent elderly mistreatment.

\section{Limitations of this study:}

Ever since the experience of mistreatment in this study was based on self-reporting, underreporting of mistreatment is a potential drawback. Information may also be underreported due to the exclusion of older adults with severe cognitive impairment who may be at increased risk for mistreatment.

\section{References}

- Abd El-Rahman, T., \& El-Gaafary M. (2012): Elder mistreatment in a rural area in Egypt. Geriatr Gerontol Int. 12(3):532-7.

- Abdelmoneium, A.O., \& Alharahsheh, S.T. (2016): Family Home Caregivers for Old Persons in the Arab Region: Perceived Challenges and Policy Implications. Open Journal of Social Sciences, 4; 151-164.

- Acierno, R., Hernandez, M.A., Resnick, H.S., Steve, K., Muzzy, W., \& Kilpatrick, D.G. (2010): Prevalence and correlates of emotional, physical, sexual, and financial mistreatment and potential neglect in the United States. The National Elder Mistreatment Study. American Journal of Public Health. 100 (2): 292-7.

- Ahmed, A.B., Mohammed, O.A., \& Abd-Elsalam, E.A. (2015): Patterns of Physical, Emotional and Financial of Elderly Mistreatment in a Rural Community in Egypt. Zagazig Nursing Journal, January; 2015 Vol.11, No.1.

- Alharahsheh, S.T. (2016): Family Home Caregivers for Old Persons in the Arab Region: Perceived Challenges and Policy Implications. Open Journal of Social Sciences, 4; 151-164.

- American College of Emergency Physicians. (2016): Clinical and practice management: domestic family violence. American College of Emergency Physicians, Irving. Accessed 25 Oct 2016. http://www.acep.org/content.aspx?id=38378.

- American Psychological Association. (2014): Older Adults' Health and Age-Related Changes available

at http://www.apa.org/pi/aging/resources/guides/older. aspx.

- Ayalon, L. (2011): Abuse is in the eyes of the beholder: using multiple perspectives to evaluate elder mistreatment under round-the-clock foreign home carers in Israel. Ageing Soc. 31:499-520.

- Bagshaw, D., Wendt, S., Zannettino, L., \& Adams, V. (2017): Financial abuse of older people by family members: Views and experiences of older Australians and their family members. Australian
Social Work, 66 (1), 86-103.

- Beach, S.R., Carpenter, C.R., Rosen, T., Sharps, P., Gelles, R. (2016): Screening and detection of elder abuse: Research opportunities and lessons learned from emergency geriatric care, intimate partner violence, and child abuse. Journal of Elder Abuse and Neglect. 28(4-5): 185-216. 10.1080/08946566.2016.1229241

- Biggs, S., Manthorpe, J., Tinker, A., Doyle, M., \& Erens, B. (2009): Mistreatment of Older People in the United Kingdom: Findings from the First National Prevalence Study. Journal of Elder Abuse \& Neglect. 2009; 21(1): 1-14

- Blair, M., \& Perry, B. (2017): Family caregiving and compassion fatigue: A literature review. The Journal of the Gerontological Nursing Association, 39 (2), 14-19.

- Dillin, A., Gottschling, E., Nyström, T., \& Gottschling, N. (2014): "The good and the bad of being connected: the integrons of aging". Curr Opin Cell Biol 26: 107-12.

- Egypt Demographic and Health Survey, Ministry of Health and Population Cairo, Egypt. El-Zanaty and Associates (2015): The DHS Program, ICF International, Rockville, Maryland, USA, May 2015

- Fahmy, S.I., Ibrahim, H.K., Nofal, L.M., Shehata, S.F., El Kady, H.M. (2015): Updating indicators for scaling the socioeconomic level of families for health research. Journal of the Egyptian Public Health Association. 90:1-7.

- Family Caregiver Alliance (2018): Selected LongTerm Care Statistics, Available from: https://www.caregiver.org/selected-long-term-carestatistics. Accessed 03/01/2018

- Fearing, G., Sheppard, C.L., McDonald, L., Beaulieu, M., \& Hitzig, S.L. (2017): A systematic review on community- based interventions for elder abuse and neglect. external icon J Elder Abuse Negl. 29(2-3): 102-133. doi: 10.1080/08946566.2017.1308286.

- Ferreira-Alves, J., \& Joao Santos, A.J. (2011): Prevalence study of violence and abuse against older woman results of Portugal survey, University of Minho, Braga.

- Formosa, M. (2018): National policies for healthy ageing in Malta: Achievements and limitations. Healthy Aging Research, 7(1), 1-6.

- Fulmer, T., Guadagno, L., Paveza, G., VandeWeerd, C., Baglioni, A., \& Abraham. (2003): Profiles of older adults who screen positive for neglect during an emergency department visit. $\mathbf{J}$ Elder Abuse Negl.; 14:49-60. doi:10.1300/J084v14n01_03.71.

- Fulmer, T., Paveza, G., Abraham, I., \& Fairchild, S. (2003): Elder neglect assessment in the 
emergency department. J EmergNurs. 26 (5):43643. doi:10.1067/men. 2000.110621.

- Hall, J.E., Karch, D.L., \& Crosby, A.E. (2016): Elder Abuse Surveillance: Uniform Definitions and Recommended Core Data Elements for Use in Elder Abuse Surveillance, Version 1.0. Atlanta (GA): National Center for Injury Prevention and Control, Centers for Disease Control and Prevention.

- Jogerst, G. (2015): Geriatric Health Questionnaire. University of Iowa Hospitals and Clinics. Iowa City, IA. (Accessed March ,2015).

- Katz, S., Ford, A.B., Moskowitz, R.W., Jackson, B.A., \& Jaffe, M.W. (2016): Studies of illness in the aged. The index of ADL: a standardized measure of biological and psychosocial function. JAMA [Internet]. 1963 [cited 2016 Jan 28]; 185(12): 914-9. Available from: http://jamanetwork.com/journals/jama/articleabstract/666768

- Khan, A. (2018): Indicators of successful aging among healthy and unhealthy older adults: Role of expressed emotions and coping (unpublished doctoral dissertation). Sargodha: University of Sargodha.

- Lachera, S., Wettsteinb, A., Senna, O., Rosemanna, T., \& Haslera, S. (2016): Types of abuse and risk factors associated with elder abuse, Swiss Med Wkly. 2016; 146: w14273.

- Logan, J.E., Haileyesus, T., Ertl, A., Rostad, W.L., \& Herbst, J.H. (2019): Nonfatal Assaults and Homicides Among Adults Aged $\geq 60$ Years United States, 2002-2016. MMWR Morb Mortal Wkly Rep. 2019 Apr 5; 68(13):297-302. doi: 10.15585/mmwr.mm6813a1.

- Lynch, S., Shuster, G., \& Lobo, M. (2018): The family care-giver experience: Examining the positive and negative aspects of compassion satisfaction and compassion fatigue as caregiving outcomes. Aging \& Mental Health, 22 (11), 14241431.

https://doi.org/10.1080/13607863.2017.1364344.

- Mehra, A., Grover, S., Agarwal, A., Bashar, M., \& Avasthi, A. (2019): Prevalence of Elder Abuse and its Association with Psychiatric Morbidity in a Rural Setting, J Neurosci Rural Pract. 2019 Apr-Jun; 10(2): 218-224.

- Mishra, G., \& Schoffield, M. (2003): Validity of self -report screening for elder abuse: Journal of Women's Health Australia Study 2003; 4 (1):110120

- National Research Council. (2018): Elder Mistreatment: Abuse, Neglect and Exploitation in an Aging America. Washington, DC: National Academies Press.

- Naughton, C., Drennan, J., Lyons, I., Lafferty, A., Treacy, M., Phelan, A., O'Loughlin, A., \&
Delaney, L. (2012): Elder mistreatment and neglect in Ireland: results from a national prevalence survey. Age Ageing. 2012; 41(1): 9810.

- Nursing Home Abuse Center (2016): Nursing Home Abuse, Understanding Nursing Home Abuse. Available from: https://www.nursinghomeabusecenter.com/nursinghome-abuse. Accessed 07/01/2016

- Orfila, F., Coma-Solé, M., Cabanas, M., CegriLombardo, F., MolerasSerra, A., \& PujolRibera, E. (2018): Family caregiver mistreatment of the elderly: Prevalence of risk and associated factors. BMC Public Health, 18 (1), 167-181. https://doi.org/10.1186/s12889-018-50678.

- Perna, L., Mielck, A., Lacruz, M., Emeny, R., Holle, R., Breitfelder, A., \& Ladwig, K. (2012): Socioeconomic position, resilience, and health behavior among elderly. Public Health, 57, 341349.

- Pillemer, K., Burnes, D., Riffin, C.P., Dillard, R. \& Bulot, J. (2011): Elder financial exploitation: implication for future policy and Research in elder mistreatment. West J Emerg. Med. 12 (3): 354-356.

- Salama, A., \& Abou El-Soud, A. (2018): Caregiver burden from caring for impaired elderly: A cross-sectional study in rural lower Egypt. Italian Journal of Public Health, 9, e8662-1-e8662- 10.

- Solanki, S.L., Singhal, G., Mishra, N., \& Meharda, B. (2015): Health problems of elderly: a challenge for care Int J Cur Res Rev .2015; 1 7(5): 38-42.

- Von Heydrich, L., Schiamberg, L.B., \& Chee, G. (2018): Social-relational risk factors for predicting elderly physical abuse: an ecological bi-focal model. Int J Aging Hum Dev. 75(1):71-94.

- World Health Organization. (2015): World report on ageing and health. Geneva: WHO. Retrieved from <www.who.int/ageing/publications/world report-2015/en/

- World Health Organization (2018): Elder abuse. Retrieved from https://www.who.int/newsroom/fact-sheets/detail/elder-abuse 